\title{
Use of Lateral Calcaneal Flap for the Reconstruction of Posterior Heel Defect
}

\author{
MACHOWDHURY ${ }^{\mathrm{a}}$, T SULTANA ${ }^{\mathrm{b}}, \mathrm{S} \mathrm{HOSSAIN}^{\mathrm{c}}$, S ISLAM $^{\mathrm{d}}$
}

\begin{abstract}
Summary:
Soft tissue defect of the lateral malleolus and achilles tendon is very challenging for reconstruction due to the bony prominence and limited local tissue availability. The purpose of this study to describe our early experience of 30 patients treated with this flap for reconstruction of posterior heel defects with or without exposure of tendo-achilles.
\end{abstract}

The study was conducted at department of plastic surgery, National Institute of Traumatology and Orthopedic Rehabilitation between 2015 to 2018. Twenty five patients (20 male and 5 females) with soft tissue defects over the posterior heel underwent reconstruction using a lateral calcaneal flap. The etiology is trauma in twelve patients,

\section{Introduction}

Posterior heel and lateral calcaneum defects are often difficult in their restoration because of osseous or tendinous bed, poor area vascularization, continuous movement and high functional demands. ${ }^{1}$ The area is subject to weight-bearing and shearing force that exceed those of any other area of the body. Therefore a defect of the heel can be difficult problem for the patient because of the inability to wear normal shoes. ${ }^{2}$ Although the amount of soft tissue around the ankle is limited and thin, local flaps are still be used because of their simplicity and reliability. ${ }^{3}$ Many reports have been published on methods of reconstruction of soft tissue defect of the heel, which

a. Dr. Maruf Alam Chowdhury, Assistant professor, Department of Plastic Surgery, National Institute of Traumatology and Orthopedic rehabilitation, Sher-EBangla Nagar, Dhaka, Bangladesh.

b. Dr. Taslima Sultana, Assistant professor, Department of Plastic Surgery, National Institute of Traumatology and Orthopedic rehabilitation, Dhaka Sher-E-Bangla Nagar, Dhaka, Bangladesh

c. Dr. Shakhawat Hossain, Assistant professor, Department of Plastic Surgery, National Institute of Traumatology and Orthopedic rehabilitation, Sher-E-Bangla Nagar, Dhaka, Bangladesh.

d. Dr. Saiful Islam, Medical Officer, Department of Plastic Surgery, National Institute of Traumatology and Orthopedic rehabilitation, Sher-E-Bangla Nagar, Dhaka, Bangladesh.

Address of Correspondence: Dr. Maruf Alam Chowdhury, Assistant professor, Department of Plastic Surgery, National Institute of Traumatology and Orthopedic rehabilitation, SherE-Bangla Nagar, Dhaka, Bangladesh. Cell : 01711675985, Email: maruf.alam.chowdhury@gmail.com

Received: 25 July, 2019 Accepted: 20 March, 2020 chronic ulcer in four and surgical wound dehiscence for repair of Tendo-Achilles in nine patients. Patients age range from 15 to 60 years (mean 35yrs) and follow up period ranged from 6 months to 2 years(mean 1 yr).

All flaps had good perfusion and survived completely. In 3 cases there was partial loss of skin graft managed conservatively. The lateral calcaneal flap can be used safely to provide sensory skin coverage of posterior heel in single stage.

Key Words : Soft tissue defects, Lateral Calcaneal Flap, Tendo-Achillis

(J Bangladesh Coll Phys Surg 2020; 38: 116-120) DOI: https://doi.org/10.3329/jbcps.v38i3.47058

include skin grafts, local skin flaps, cross leg flaps, muscle flaps, musculocutaneous flaps and free flaps. ${ }^{4}$

Lateral calcaneal flap, which were first reported by Grab and Argenda in 1981, have been used as a mean of reconstructing skin defects over the calcaneus on its posterior surface. ${ }^{5}$ It is an axial pattern flap that includes lesser saphenous vein, the sural nerve and the lateral calcaneal artery. ${ }^{1}$ Its advantages include adequate coverage of posterior heel and lateral calcaneum, high success rate, low postoperative morbidity and good functional results. ${ }^{1}$

Modification of this flap is an island flap, distally based flap, free flap, V-Y advancement flap and adipofascial flap for wide variety of clinical applications have been reported.

The purpose of this study is to describe our early experience of 30 patients treated with various modifications of this flap for reconstruction of posterior heel defects with or without exposure of tendo-Achilles.

\section{Materials and methods}

The study was conducted at department of Plastic Surgery, National Institute of Traumatology and Orthopedic Rehabilitation between 2015 to 2018. Twenty five patients(20 male and 5 female) with soft tissue defects over the posterior heel underwent reconstruction using a lateral calcaneal artery fasciocutaneous flap soft tissue defects were caused by acute trauma in twelve patients, chronic ulcer in four and surgical wound dehiscence for repair of tendoAchilles in nine patients. 


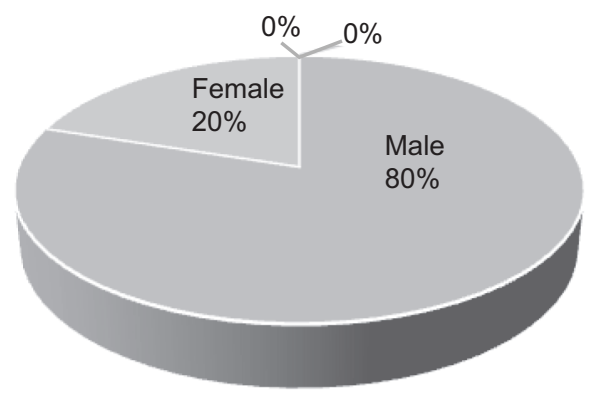

Fig.-1: Pie chart showing sex distribution of study subjects

The patient's age ranges from 15 to 60 years (mean 35 years) and the follow-up period ranged from 6 to 2 years (mean 1 year).

The position and course of the Calcaneal artery is marked on the skin. We based the design of the flap on the estimated course of the lateral calcaneal artery, using 3 anatomical landmarks. First landmark was origin of Lateral Calcaneal Artery (LCA) from peroneal artery,

Table-I

\begin{tabular}{lcc}
\multicolumn{3}{c}{ Distribution of Study Subjects by Aetiology } \\
Aetiology & Patients No & Percentage \% \\
\hline Acute trauma & 12 & 48 \\
Chronic Ulcer & 4 & 16 \\
Wound Dehiscence & 9 & 36 \\
\hline
\end{tabular}

Table-II

\begin{tabular}{lcc}
\multicolumn{3}{c}{ Distribution of Study Subjects by Age } \\
Age Range & Patients No & Percentage\% \\
\hline $10-20$ & 2 & 8 \\
$20-30$ & 2 & 8 \\
$30-40$ & 6 & 24 \\
$40-50$ & 9 & 36 \\
$50-60$ & 6 & 24 \\
\hline
\end{tabular}

approximately $6 \mathrm{~cm}$ above the middle of the line connecting lateral malleolus and insertion of Achilles tendon. Second landmark was the middle of the line connecting between lateral malleolus and insertion of Achilles tendon. Third landmark was $1 \mathrm{~cm}$ proximal to the tuberosity of the fifth metatarsal. Dissection of the flap began from distal to proximal. Then dissection continued along the course of LCA from distal to proximal so as to identify its area of vascularization. Distance between lateral malleolus and LCA was measured, as was flap's pivot point.

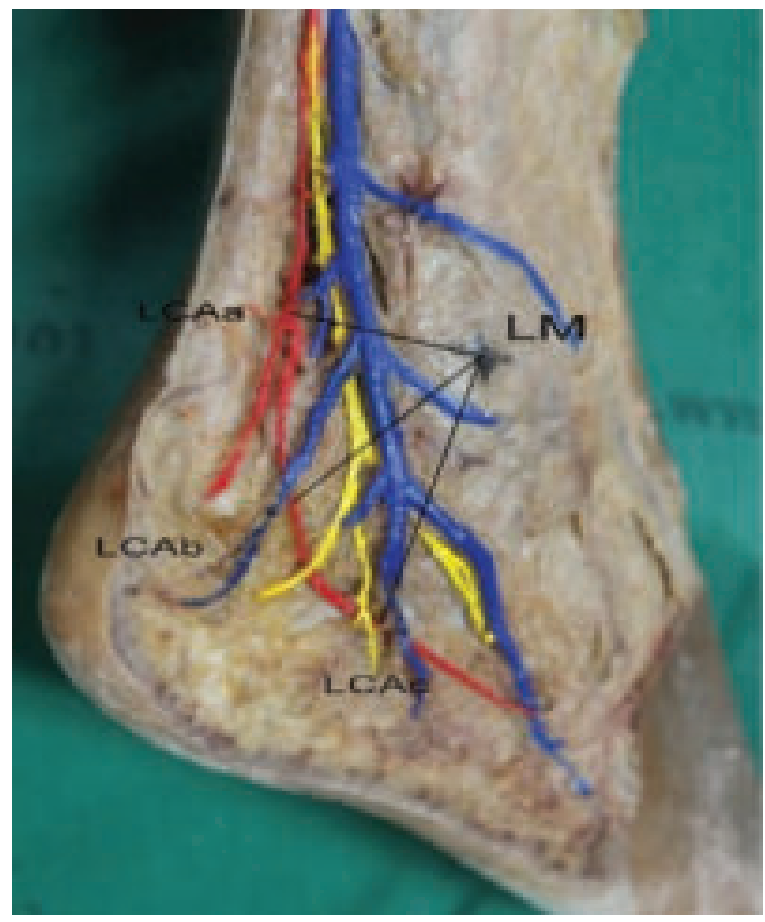

Fig.-2: The lateral side of the right cadaveric foot is shown. The distance between the LCA and the most prominent point of the LM was measured horizontally (LCAa-LM), at 45 degrees ( $L C A b-L M)$, and vertically (LCAC-LM). The red, blue, and yellow lines represent the LCA, lesser saphenous vein, and sural nerve, respectively. ${ }^{15}$

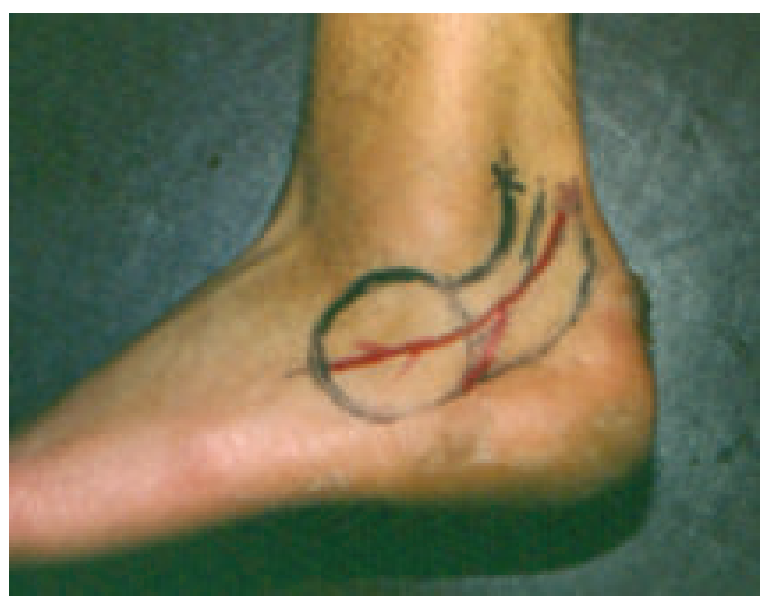

Fig-3: Preoperative design of the flap. ${ }^{1}$ 
Surgical procedure was performed under a tourniquet and surgical loupes of 2.5 magnification. The defect was measured at its two maximal dimensions after wound excision and then the flap was marked on skin. Dissection is begun at the lateral aspect of the calcaneal region and is carried out distally to the periosteum of the calcaneus. The plain is then developed leaving the periosteum intact. The anterior incision is made immediately behind the lateral malleolus and carried down through the subcutaneous tissue. Finally the distal horizontal incision is made and the flap is raised in a retrograde fashion. Optimally the vessels are not exposed and therefore not traumatized. Dissection is carried out in a

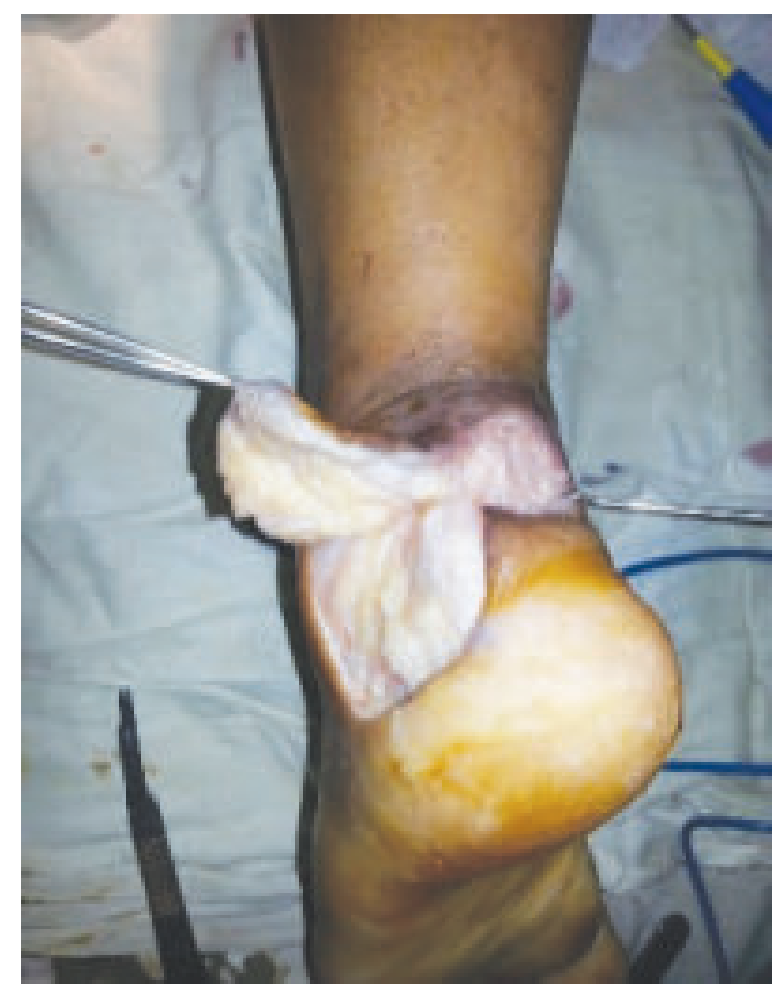

Fig-4: Flap Elevation

retrograde fashion to the level of the lateral malleolus. The pedicle of both versions of the flap lies immediately above the level of the lateral malleolus. Immediately above the malleolus the calcaneal artery begins to sink to a deeper level. A minimum amount of dissection can facilitate rotation but deeper dissection may be dangerous. The base of the flap usually left intact and optimally should be at least $4 \mathrm{~cm}$ wide. If the flap is elevated as an island, care must be taken to avoid trauma to the lesser saphenous vein during dissection. Rotation to the defect is then performed and the flap is inset. No deeper sutures are used. A split thickness skin graft is placed over the donor defect and immobilized with a tie over dressing. Postoperatively the patient is kept in bed with the leg elevated for 5 to 7 days.

\section{Results}

The lateral calcaneal flap has been used for sensate reconstruction of heel defects in 30 patients. All flaps had good perfusion and survived completely. In 3 cases there was partial loss of skin graft and later developed hypertrophied scar which was managed

Case 1: 32yrs old Patient with post traumatic wound in left foot with exposed Tendo-Achilles; treated with Lateral calcaneal artery flap.

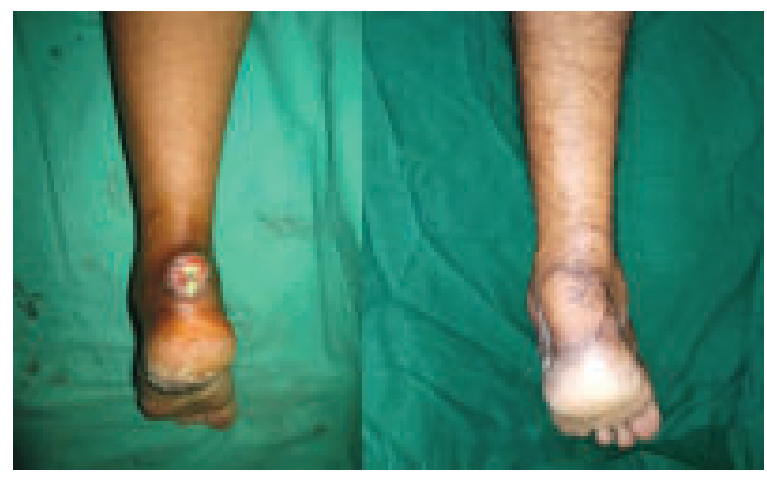

Case 2: 60 yrs old Patient with Non-healing ulcer in left foot; treated with Lateral Calcaneal Artery Flap conservatively. Dog ear deformity occurred in 5 cases where flap needed much rotation. In 3 cases correction of dog ear deformity was done after 3-4 months with local anaesthesia. Transient hyperesthesia at the lateral aspect of the foot was recorded in all patients.

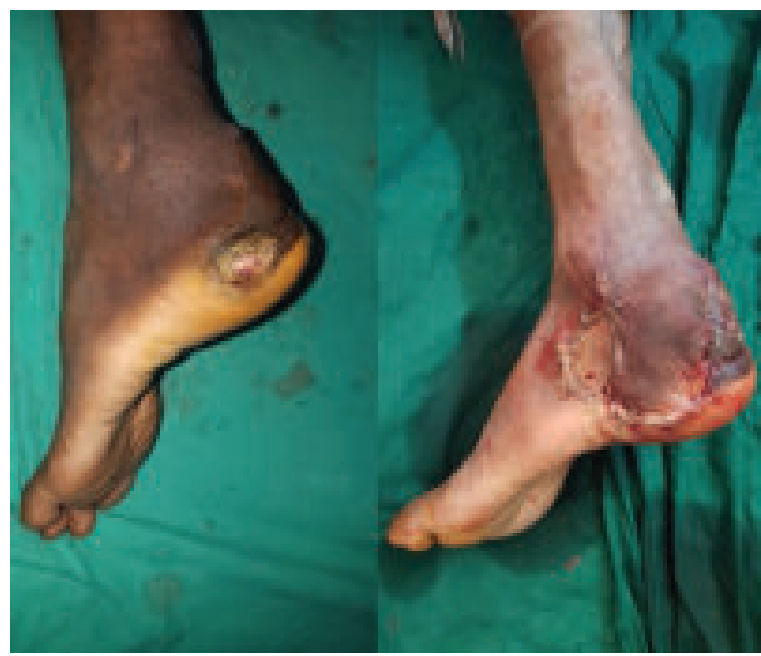


Case 3: 35yrs old lady with expoed Tendo-Achilles(left); treated with Lateral calcaneal artery flap

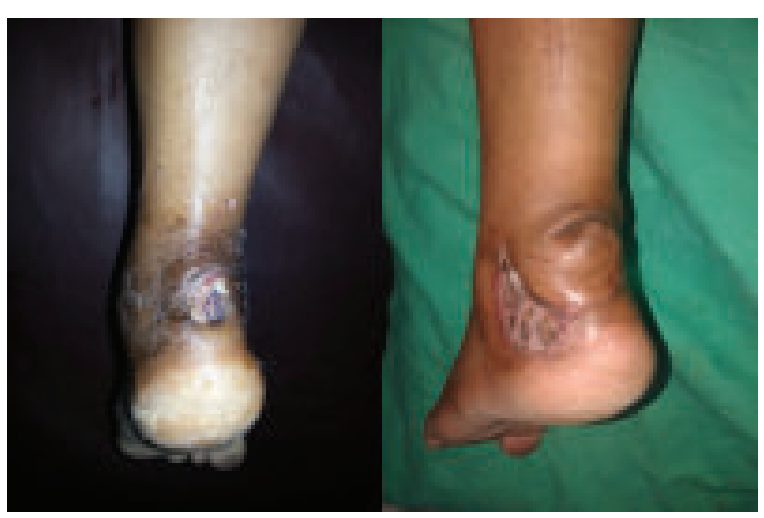

All patients become ambulatory after wound healing and ankle movement was not restricted. There was no subsequent breakdown of the flap and the grafted skin with the regular wearing of shoes.

\section{Discussion}

Reconstruction of soft tissue defects of calcaneal region and posterior heel is demanding because of their osseous or tendinous bed, poor vascularization and constant area movement. Their restoration necessitates tissue with reliable blood supply, adequate elasticity and sensitivity. ${ }^{1}$ There are many methods for reconstruction of these region. For this purpose, methods ranging from skin grafts to microsurgical flaps have been used, each with some advantage and disadvantages for many years. The distally based reverse sural flap is the best well known flap for reconstruction of the patients heel. It's broad spectrum of indications, longer vascular territory and great arc of rotation combined to make it a substitute for free tissue transfer for treatment of larger and composite defects. But it is not a good match for the defects of the posterior heel as it is more bulky, insensate, usually leaves longer linear scar cutting across the ankle and skin grafting is needed in calf region. ${ }^{8}$ Simple method like skin grafting may also be useful in specific situations but it often leads to unacceptable results.$^{9}$ Lateral calcaneal flap is an axial pattern fasciocutaneous flap that is simple, stable and sensate. It is nourished by the lateral calcaneal artery, which is a terminal branch of peroneal artery, is drained by the lesser saphenous vein and is innervated by the sural nerve. ${ }^{2}$ It is preferred in small sized isolated posterior heel defect with exposed tendo-Achilles or calcaneum and normal skin flap viscinity. ${ }^{3}$ Peroneal vessels are last to be affected by age, diabetes mellitus or smoking, making it a safe flap in these patients. ${ }^{7}$ Because these fasciocutaneous flap is moved as a transposition flap from the area below the lateral malleolus so dog ear or kinking of the pedicle may occur. ${ }^{2}$ Disadvantage of the flap are that donor site requires grafting which is put on the periosteum giving a depression and causes a poor cosmetic appearance. Patients also have sensory disturbance at the lateral part of the dorsum of foot. ${ }^{10}$ In their series of 10 patients by MT Islam et al, two of the donor sites had partial loss of skin graft which were healed conservatively with regular dressings. In our series of 25 patients 3 had partial graft loss in donor site and developed hypertrophied scar which were managed conservatively.

There are many modifications of lateral calcaneal flap. Island modifications of this flap has been described to prevent the problems associate with classic lateral calcaneal skin flap such as kinking in the pedicle, dog ear deformity and the need for sacrificing the normal skin bridge for flap inset. ${ }^{11}$ It also has greater arc of rotation but it could not solve the problem associates with the donor site area. ${ }^{12}$ Another disadvantage of island lateral calcaneal flap is possible compression of the pedicle by the skin bridge between the donor site and recipient site which eventually compromise the circulation of the flap. The lateral calcaneal V-Y advancement flap eliminates this disadvantage. ${ }^{13}$ This modification preferred by M. Eron Demerseren et al. In their study out of 18 patients were reconstructed with lateral calcaneal island flap and the lobed shaped lateral calcaneal advancement flap. In our study no patients were reconstructed with these modifications. Only one patient was reconstructed with distally based lateral calcaneal flap which survived completely.

Another modification is lateral calcaneal adipofascial flap. Use of lateral calcaneal adipofascial flap was reported for small defects on posterior heel. ${ }^{14}$ The advantage of this type of adipofascial flap are that it preserves sural nerve and does not require skin grafting of the donor site. ${ }^{3}$

The adipofascial flap is more versatile than skin flap because it can be used with either its fascial or adipose tissue side to cover tissue defects. The adipofascial flap was soft and pliable and could be transferred 
smoothly without the formation of a dog ear or kinking of the pedicle. ${ }^{3}$ Moonsong Cheeng et al reported five patients flap had good perfusion and survived completely. In their study all patients become ambulatory after wound healing and ankle mortis was not restricted. There is no subsequent breakdown of grafted skin with regular wearing of shoes. In our study we did not perform adipofascial flap as it did not avoid Skin grafting.

\section{Conclusion}

Lateral calcaneal flap presents good functional and aesthetic results for coverage of posterior heel and lateral calcaneal defect. Its advantages are its good functional results, its small perioperative morbidity and relative easiness for its design and creation. The flap is also resistant to atherosclerosis, a common problem in elderly patient with heel defect.

Conflict of Interest: The authors have no Conflict of interest regarding the publication of this paper.

\section{References:}

1. Zygouris P, Mechalinos A, Protogerou V, Kotsiomitis E et a1. "Use of Lateral Calcaneal for coverage of hindfootdefects:An Anatomical Appraisal" Plastic Surgery International, volume 2015, article ID 212757,5 page

2. Anwer A, Anwar M,Tariq M, "Versatility of Lateral Calcaneal Artery Skin for Coverage of Posterior Heel Defects-Our Experience" Pakistan journal of Medical and health Sciences,2013 July ;7(3):679-683

3. Lin S-D,Lai C-S,Chiu Y-T,Lin T-M "The lateral Calcaneal Artery Adipofascial flap" British journal of plastic surgery 1996,49(1);52-57

4. Levin L.S. "Foot and ankle soft tissue deficiencies:who needs a flap?" Am J Ortho(Belle mead NJ).2006 Jan;35(1):11-9
5. Omokawa S, Yajima H,Tanaka Y,Ryu J, "Long Term Results of Lateral Calcaneal ArteryFlap for Hindfoot Reconstruction"J Reconstructive Microsurgery 2008 May,24;239-246

6. Ercocen A.R., Can Z, Yormuk E, "The Lateral calcaneal Island flap for sensate coverage of heel defects"Eur J PlastSurg(1998) 21:299-302

7. Demirseren M.E, Gokrem S,Can Z "Reappraisal of Island Modifications of Lateral Calcaneal Artery Skin Flap"Plast Reconstructive Surg.2004 April; 113(4)1167-74

8. Cheema TA, Saleh ES, De carvalho AF. "The Distally Based sural artery flap for ankle and foot coverage".J Foot ankle Surg 2007;46(1)40-7

9. Islam MT, Abdullah SN, Uddin MJ, Rahman TR "Use of Lateral Calcaneal Flap for coverage of posterior heel defects" Mediscope 2017; 4(1): 5-10

10. Zhang FH, Chang SM, LIN SQ, Song YP, Zheng HP, Lineaweaver WC, Zhang F. "Modified distally based suralneuro-veno-fasciocutaneous flap:anatomical study and clinicalapplications" Microsurgery.2005;25(7):543-550

11. Li L, Xue C, Li J,Zhang J,Xing X et el. "Application of flap in repair of heel skin and soft tissue defect" Zhongguo Xiu Fu Chong JianWaiKeZhi. 2008Jul;22(7):800-2.Chinese

12. Hovius SE, Hofman A, Vander meulan JC. "Experience with the Lateral Calcaneal Artery Flap" Ann PlastSurg 1988:21:532-5

13. Hayashi A and Maruyama Y. "Lateral Calcaneal V-Y Advancement flap for repair of posterior heel defects" Plast.Reconstr.Surg 1999Feb ;103(2): 577-80

14 Chang MS, Baek GH,Rhee SHet el. "Lateral Calcaneal artery adipofascial flap for reconstruction of the posterior heel of the foot" Clinics in Orthopedic Surgery 2009;1:1-5

15. Burusapat $C$, Tanthanatip $P$, Suwanemee $C$ et el. "Lateral Calcaneal Artery Flap in Atherosclerosis: Cadaveric Study, Vascular Assessment and Clinical Applications" plastic and reconstructive surgery 2015 . 